\title{
PENGARUH KOMITMEN ORGANISASIONAL DAN PROFESIONAL TERHADAP KEPUASAN KERJA DENGAN MOTIVASI SEBAGAI VARIABEL INTERVENING PADA PEGAWAI UPT DINAS KESEHATAN PUSKESMAS AIR BANGIS PASAMAN BARAT
}

\author{
Putri Permata Sari, Aminar Sutra Dewi \\ Sekolah Tinggi Ilmu Ekonomi KBP \\ putripuspitasari@gmail.com
}

\begin{abstract}
This research was conducted at the Department of Health UPT Puskesmas Aia Bangih excl. Beremas River District. Pasaman Barat. The purpose of this research are: 1) To analyze the Influence of organizational commitment on job satisfaction in the Employee Health Office UPT Puskesmas Aia Bangih excl. Beremas River District. Pasaman Barat, 2) To analyze the professional Influence on job satisfaction in the Employee Health Office UPT Puskesmas Aia Bangih excl. Beremas River District. Pasaman Barat, 3) To meganalisis Influence of motivation on job satisfaction in the Employee Health Office UPT Puskesmas Aia Bangih excl. Beremas River District. Pasaman Barat. This type of research is qualitative research. The object of this study are employees of PT. Regional Development Bank of West Sumatra Health Office Branch Siteba UPT Puskesmas Aia Bangih excl. Beremas River District. Pasaman Barat. Data analysis method used is descriptive analysis and multiple linear regression analysis. Based on the research results obtained the following conclusions: 1) organizational commitment partially no effect on employee satisfaction UPT Puskesmas Health Department Air Bangis. 2) Professional positive and significant effect partially on employee satisfaction UPT Puskesmas Health Department Air Bangis. 3) Motivation positive and significant effect partially on employee satisfaction UPT Puskesmas Health Department Air Bangis.
\end{abstract}

Keywords: organizational commitment, professional, Motivation and Job Satisfaction

\section{PENDAHULUAN}

Sumber daya manusia merupakan salah satu faktor yang sangat penting dalam suatu perusahaan di samping faktor yang lain seperti modal. Oleh karena itu, sumber daya manusia harus dikelola dengan baik untuk meningkatkan efektivitas dan 
efisiensi organisasi, sebagai salah satu fungsi dalam perusahaan yang dikenal dengan manajemen sumber daya manusia.

Profesional merupakan peristiwa dimana individu sangat tertarik pada (mempunyai keterikatan terhadap) nilai-nilai, aturan-aturan, dan tujuan dari profesinya. Seorang profesional dalam menjalankan tugasnya pasti akan berdasarkan pada prilaku, sikap dan orientasi terhadap profesinya tersbut, hal ini akan memunculkan loyalitas pada profesinya. Profesional di puskesmas tersebut masih belum mendukung dimana terlihat belum melayani pegawai dalam menjalankan tujuaanya di puskesmas.

Motivasi adalah keadaan dalam pribadi seseorang yang mendorong keinginan individu untuk melakukan kegiatan-kegiatan tertentu untuk mecapai suatu tujuan (Reksohadiprojo dan Handoko, 2000). Motivasi merupakan hasil interaksi antara individu dan situasinya, sehingga setiap manusia mempunya inovasi yang berbeda antara yang satu dengan yang lainnya (Badjuri, 2008). Selanjutnya Robbins(2008) menyatakan bahwa ada 3 kata kunci utama tentang motivasi dalam perilaku organisasi yaitu: kemauan untuk berusaha, pencapaian dan tujuan organisasi. Dengan adanya komitmen organisasional pada seseorang akan menimbulkan motivasi untuk bekerja sebaik-baiknya pada suatu organisasi dalam upaya mewujudkan tujuan bersama, karena motivasi merupakan proses atau faktor yang mendorong orang untuk bertindak atau berprilaku dengan cara cara tertentu sesuai komitmennya (Trisnaningsih, 2003). Dimana di puskesmas kurangnya motivasi-motivasi yang diberikan kepada pegawai seperti masih adanya pegawai yang bertindak atau berprilaku tidak sesuai dengan komitmennya.

Penelitian Badjuri (2009), yang meneliti tentang pengaruh komitmen terhadap kepuasan kerja auditor terhadap kepuasan kerja auditor dengan motivasi sebagai variabel intervening, dengan obyek KAP di Jawa Tengah.Hasil dari penelitian adalah komitmen organisasi dan komitmen profesional berpengaruh terhadap kepuasan kerja melalui motivasi sebagai variabel intervening,demikian juga penelitian Reksohadiprodjo (2003), RaharjodanWaridin (2000), memberikan bukti yang sama. Sedangkan penelitian Trisnaningsih (2004) dengan menggunakan obyek akuntan pendidik di kota Surabaya diperoleh hasil bahwa komitmen organisasi dan komitmen profesional berpengaruh terhadap kepuasan kerja tidak melalui motivasi sebagai variabel intervening, atau motivasi sebagai variabel moderating pengaruh antara komitmen organisasi terhadap kepuasan kerja.

Berdasarkan uraian latar belakang diatas yang belum menunjukkan hasil yang konsisten maka peneliti tertarik untuk melakukan penelitian yang berjudul "Pengaruh Komitmen Organisasional dan Profesional terhadap Kepuasan Kerja dengan Motivasi sebagai Variabel Intervening pada Pegawai UPT Dinas Kesehatan Puskesmas Aia Bangih kec. Sungai Beremas Kab. Pasaman Barat."

\section{LANDASAN TEORI}

Menurut Spector (2000) kepuasan kerja merupakan variabel sikap yang merefleksikan apa yang di rasakan seseorang mengenai pekerjaannya. Pertanyaan 
tersebut sejalan dengan pendapat riggio (2000) dalam Ciliana (2008) kepuasan kerja merupakan perasaan dan sikap seseorang mengenai pekerjaannya. Selain itu Robbins (2003) juga memandang kepuasan kerja sebagai sikap seseorang terhadap pekerjaannya sebagai hasil penilayan terhadap perbedaan antara jumlah ganjaran positif yang iya terima dengan jumlah yang ia percaya sharusnya ia terima.

Anik dan Arifudin (2005) mengatakan bahwa kepuasan kerja adalah suatu tingkat perasaan yang positif/negatif tentang beberapa aspek dari pekerjaan, situasi kerja dan hubungan dengan rekan sekerja. Kepuasan kerja tergntung pada tingkat perolehan instrinsik dan ekstrinsik pada pandangan pekerja terhadap perolehan tersebut. Tingkat perolehan mempunyai tingkat yang berbeda-beda. Bagi orang tertentu, pekerjaan yang penuh tanggung jawab dan yang menantang mungkin menghasilkan perolehan yang netral atau bahkan negatif, bagi orang lain perolehan pekerjaan semacam ini mungkin mempunyai nilai yang positif. Orang mempunyai nilai (valensi) yang berbeda-beda, yang di kaitkan dengan perolehan pekerjaan. Perbedaan tersebut akan menimbulkan perbedaan kepuasan tingkat bekerja bagi tugas pekerjaan yang intinya sama.

Kepuasan kerja dapat pula di defenisikan sebagai keadaan emosi yang menyenangkan sebagai hasil presepsi seseorang terhadap pekerjaannya, apakah pekerjaan tersebut dapat memenuhi atau memfasilitasi tercapainya pemenuhan nilai pekerjaan yang penting bagi orang tersebut. Kepuasan kerja sebagai cara pandang seseorang terhadap pekerjaannya, apakah ia memandang pekerjaannya sebagai sesuatu yang menyenangkan atau sebagai sesuatu yang tidak menyenangkan (Ciliana, 2008).

Kepuasan kerja (job satisfaction) adalah suatu sikap yang dimiliki pekerja mengenai pekerjaan mereka.Hal ini dihasilkan dari persepsi mereka mengenai pekerjaan (Ivancevich, John M., dkk; 2005). Menurut Robbins, Stephen P., dan Timothy A. Judge (2007) kepuasan kerja dapat didefinisikan sebagai perasaan positif tentang pekerjaan seseorang yang merupakan hasil dari evaluasi karakteristikkarakteristiknya.

Kepuasan kerja merupakan seperangkat perasaan karyawan tentang menyenangkan atau tidaknya pekerjaan mereka, yang menunjukkan kesesuaian antara harapan kerjanya dengan manfaat yang ia terima dalam perusahaan (Luthans, Fred, 2006). Kreitner, Robert dan Angelo Kinicki (2000) mendefinisikan kepuasan kerja adalah suatu efektivitas atau respon emosional terhadap berbagai aspek pekerjaan.

Howell dan Dipboye (dalam Munandar; 2011) memandang kepuasan kerja sebagai hasil dari derajat suka atau tidak sukanya tenaga kerja terhadap berbagai aspek pekerjaannya.

Tampubolon, Manahan P. (2008) berpendapat bahwa kepuasan kerja karyawan dalam suatu kelompok kerja atau organisasi pada kahirnya akan digambarkan sebagai tingkat produktivitas kerja karyawan, tingkat kehadiran/absen, serta keluar dan masuk (turnover rates) dalam suatu organisasi.

Menurut Robbins (2008), komitmen karyawan terhadap organisasi yaitu sampai tingkat mana seorang pegawai memihak pada suatu organisasi tertentu dan 
tujuan-tujuannya, serta berniat memelihara keanggotaan dalam organisasi tertentu. Karyawan yang memiliki komitmen adalah karyawan yang menunjukkan keterlibatan yang tinggi dalam suatu organisasi (Darmawan, 2013).

Mowday, dkk (1982) seperti dikutip oleh Darmawan (2013) mendefinisikan komitmen sebagai kuatnya pengenalan dan keterlibatan karyawan dalam suatu organisasi tertentu, sedangkan Becker (1960) seperti dikutip oleh Darmawan (2013) menyatakan komitmen sebagai kecenderungan untuk terikat dalam garis kegiatan yang konsisten karena menganggap adanya biaya pelaksanaan kegiatan yang lain.

Profesional adalah tingkat loyalitas individu pada profesinya seperti yang telah dipersepsikan oleh individu tersebut. Agar seseorang dapat berperilaku dengan baik, maka ia harus memperhatikan etika profesional yang diatur dalam kode etik. Etika profesional yaitu standard perilaku seseorang profesional yang dirancang untuk tujuan praktis dan idealistik sehingga mendorong perilaku seseorang yang ideal, bersifat realistis, dan dapat dipertanggungjawabkan secara hukum. Dalam suatu asosiasi profesi ditekankan akan adanya tingkat komitmen yang setinggi-tingginya yang diwujudkan dengan kerja berkualitas sekaligus sebagai jaminan keberhasilan atas tugas yang dihadapinya.

Profesional adalah tingkat loyalitas pada profesinya seperti yang di persepsikan oleh individu tersebut (Larkin1990). Wibowo (1996) mengungkapkan bahwa tidak ada hubungan antara pengalaman internal auditor dengan profesional, lama bekerja hanya mempengaruhi pandangan profesional, hubungan dengan sesama profesi, keyakinan terhadap peraturan profesi dan pengabdian pada profesi. Hal ini di sebabkan bahwa semenjak awal tenaga profesional telah dididik untuk menjalankan tugas-tugas yang komplek secara independen dan memcahkan permasalahan yang timbul dalam pelaksanaan tugas-tugas dengan menggunakan keahlian dan dedikasi mereka secara profesional (Schwartz,1996) dalam Trisnaningsih (2003).Pemberian jasa profesional yang kompeten membutuhkan pertimbangan yang cermat dalam menerapkan pengetahuan dan keahlian profesional. Kompetensi profesional dapat di bagi menjadi dua tahap yang terpisah yaitu pencapaian kompetensi profesional dan pemliharaan kompetensi profesional. Pemeliharaan kompetensi profesional membutuhkan kesadaran dan pemahaman yang berkelanjutan terhadap perkembangan teknis profesi dan perkembangan bisnis yang relevan.

Pengembangan dan pendidikan profesional yang berkelanjutan sangat di perlukan untuk meningkatkan dan memlihara kemampuan praktisi agar dapat melaksanakan pekerjaannya secara kompeten dalam lingkungan profesional menurut SPAP (2011:11).

\section{METODE PENELITIAN}

Berdasarkan masalah yang akan diteliti pada penelitian ini maka jenis penelitian ini adalah penelitian kuantitatif dan penelitian kualitatif. Penelitian kualitatif memberikan gambaran respon sampel penelitian pengaruh komitmen organisasional, profesional, dan motivasi kerja terhadap kepuasaan kerja. Penelitian kuantitatif data yang berbentuk angka yaitu untuk menganalisa penelitian pengaruh 
komitmen organisasional terhadap kepuasan kerja pada PegawaiUPT Dinas Kesehatan Puskesmas Aia Bangih kec. Sungai Beremas Kab. Pasaman Barat.

Objek penelitian ini adalah Pegawai UPT Dinas Kesehatan Puskesmas Aia Bangih kec. Sungai Beremas Kab. Pasaman Barat

Arikunto (2002) berpendapat "populasi adalah keseluruhan subjek penelitian". Populasi juga dapat dikatakan sebagai subjek yang dikenai kesimpulan penelitian. Penentuan responden dilakukan secara strifield random yaitu dengan mengambil responden yang paling mengetahui keadaan organisasi (Sugiyono, 2005 ).Populasi dalam penelitian ini adalah pegawaiUPT Dinas Kesehatan Puskesmas Aia Bangih kec. Sungai Beremas Kab. Pasaman Barat yang berjumlah 50 pegawai.

Menurut Arikunto (2002: 104) sampel adalah bagian atau wakil dari populasi yang diteliti. Pengambilan sampel secara sederhana diartikan sebagian dari populasi yang menjadi sumber daya yang sebenarnya dalam penelitian. Teknik pengambilan sampel dalam penelitian ini adalah total sampling. Total sampling adalah teknik pengambilan sampel dimana jumlah sampel sama dengan populasi (Sugiyono, 2007). Alasan mengambil total sampling karena menurut Sugiyono (2007) jumlah populasi yang kurang dari 100 seluruh populasi dijadikan sampel penelitian semuanya. Sampel dalam penelitian ini adalah pegawaiUPT Dinas Kesehatan Puskesmas Aia Bangih kec. Sungai Beremas Kab. Pasaman Barat sebanyak 50 pegawai.

Data kualitatif adalah data yang bukan berbentuk angka-angka atau bilangan tetapi berupa keterangan atau informasi serta keterampilan, aktifitas, sifat, dan sebagainya. Dalam hal ini data kualitatif antara lain data-data mengenai sejarah perkembangan perusahaan dan data-data responden pegawaiUPT Dinas Kesehatan Puskesmas Aia Bangih kec. Sungai Beremas Kab. Pasaman Barat.

Data kuantitatif adalah data yang diukur dan biasanya berupa angka-angka bilangan. Dalam hal ini antara lain data tentang ukuran populasi dan sebagiannya.

Menurut Sugiarto (2002) data primer merupakan data yang didapat dari sumber pihak pertama baik dari individu maupun perseorangan.Pada penelitian ini, data primer adalah data yang diperoleh secara langsung dari sumbernya, diamati, dan dicatat untuk pertama kalinya melalui wawancara atau hasil pengisian kuesioner kepada responden penelitian yang dijadikan sampel yaitu karyawan UPT Dinas Kesehatan Puskesmas Aia Bangih kec. Sungai Beremas Kab. Pasaman Barat.

Data sekunder adalah data yang diperoleh secara tidak langsung, baik berupa keterangan maupun literatur yang ada hubungannya dalam penelitian yang sifatnya melengkapi atau mendukung data primer. Data sekunder diperoleh dari berbagai bahan pustaka, baik berupa buku, jurnal-jurnal dan dokumen lainnya yang ada hubungannya dengan materi kajian.

Linear berganda adalah alat statistik yang digunakan untutk mengetahui pengaruh antara satu atau beberapa variabel terhadap satu buah variabel.Variabel yang memengaruhi sering disebut variabel bebas, variabel independen atau variabel penjelas.Variabel yang dipengaruhi sering disebut dengan variabel terikat atau variabel dependen.Regresi linear hanya dapat digunakan pada skala interval dan ratio. 
Secara umum regresi linear terdiri dari dua yaitu regresi linear sederhana yaitu dengan satu buah variabel bebas dan satu buah variabel terikat, namun dalam penelitian ini penulis menggunakan regresi linear berganda, karena dalam penelitian ini penulis menggunakan lebih dari satu variabel.

\section{HASIL DAN PEMBAHASAN}

Profil Kesehatan Kabupaten/Kota merupakan salah satu sarana untuk menggambarkan situasi dan kondisi kesehatan masyarakat di satu wilayah dan merupakan salah satu sarana untuk mengevaluasi hasil penyelenggaraan pembangunan kesehatan. UPT Dinas Kesehatan Puskesmas Air Bangis terletak di Kecamatan Air Bangis Kabupaten Pasaman Barat.

Visi dan Misi UPT Dinas Kesehatan Puskesmas Air Bangis

Visi dan Misi merupakan pedoman yang paling mendasar bagi arah pengembangan UPT Dinas Kesehatan Puskesmas Air Bangis di masa yang akan datang.

1. Visi

Tercapainya Kecamatan Sehat menuju terwujudnya Indonesia Sehat.

2. Misi

1) Menggerakkan pembangunan berwawasan kesehatan.

2) Mendorong kemandirian hidup sehat bagi keluarga dan masyarakat.

3) Memelihara dan meningkatkan mutu, pemerataan dan keterjangkauan pelayanan kesehatan yang diselenggarakan.

4) Memelihara dan meningkatkan kesehatan perorangan, keluarga dan masyarakat beserta lingkungannya.

3. Tujuan Puskesmas

Mendukung tercapainya tujuan pembangunan kesehatan nasional, yakni meningkatkan kesadaran, kemauan, dan kemampuan hidup sehat bagi setiap orang yang bertempat tinggal di wilayah kerja Puskesmas agar terwujud derajat kesehatan yang setinggi - tingginya dalam rangka mewujudkan Indonesia Sehat.

4. Fungsi Puskesmas

Puskesmas memiliki fungsi untuk mengembangkan pelayanan kesehatan yang bersifat menyeluruh atau yang disebut dengan Comprehensive Health Care Service yang meliputi aspek promotive, preventif, curative, dan rehabilitatif.

5. Motto Puskesmas UPT Dinas Kesehatan Puskesmas Air Bangis 
Tabel 1

Hasil Uji Validitas Variabel Komitmen Organisasional

\begin{tabular}{|l|r|r|r|r|r|}
\hline & $\begin{array}{c}\text { Scale Mean if } \\
\text { Item Deleted }\end{array}$ & $\begin{array}{c}\text { Scale Variance if } \\
\text { Item Deleted }\end{array}$ & $\begin{array}{c}\text { Corrected Item- } \\
\text { Total Correlation }\end{array}$ & $\begin{array}{c}\text { Squared Multiple } \\
\text { Correlation }\end{array}$ & $\begin{array}{c}\text { Cronbach's } \\
\text { Alpha if Item } \\
\text { Deleted }\end{array}$ \\
\hline P1 & 28.18 & 8.028 & .563 & .346 & .743 \\
P2 & 28.14 & 8.490 & .370 & .313 & .774 \\
P3 & 28.02 & 8.632 & .387 & .294 & .770 \\
P4 & 28.02 & 8.142 & .543 & .362 & .746 \\
P5 & 27.76 & 7.982 & .503 & .323 & .752 \\
P6 & 27.78 & 8.053 & .462 & .331 & .759 \\
P7 & 27.68 & 8.263 & .444 & .329 & .762 \\
P8 & 27.72 & 7.716 & .595 & .410 & .736 \\
\hline
\end{tabular}

Sumber : Data primer yang diolah, 2017

Tabel 2

Hasil Uji Validitas Variabel Profesional

\begin{tabular}{|l|r|r|r|r|r|}
\hline & $\begin{array}{c}\text { Scale Mean if } \\
\text { Item Deleted }\end{array}$ & $\begin{array}{c}\text { Scale Variance if } \\
\text { Item Deleted }\end{array}$ & $\begin{array}{c}\text { Corrected Item- } \\
\text { Total Correlation }\end{array}$ & $\begin{array}{c}\text { Squared Multiple } \\
\text { Correlation }\end{array}$ & $\begin{array}{c}\text { Cronbach's } \\
\text { Alpha if Item } \\
\text { Deleted }\end{array}$ \\
\hline P1 & 27.96 & 9.223 & .413 & .357 & .782 \\
P2 & 28.20 & 8.571 & .633 & .626 & .747 \\
P3 & 27.86 & 9.062 & .455 & .363 & .775 \\
P4 & 27.88 & 9.087 & .429 & .279 & .780 \\
P5 & 28.08 & 8.647 & .662 & .616 & .745 \\
P6 & 28.04 & 8.774 & .424 & .224 & .784 \\
P7 & 28.16 & 9.484 & .463 & .339 & .775 \\
P8 & 27.82 & 8.722 & .561 & .359 & .758 \\
\hline
\end{tabular}

Sumber : Data primer yang diolah, 2017

Tabel 3

Hasil Uji Validitas Variabel Kepuasan Kerja

\begin{tabular}{|l|r|r|r|r|r|}
\hline & $\begin{array}{c}\text { Scale Mean if } \\
\text { Item Deleted }\end{array}$ & $\begin{array}{c}\text { Scale Variance if } \\
\text { Item Deleted }\end{array}$ & $\begin{array}{c}\text { Corrected Item- } \\
\text { Total Correlation }\end{array}$ & $\begin{array}{c}\text { Squared Multiple } \\
\text { Correlation }\end{array}$ & $\begin{array}{c}\text { Cronbach's } \\
\text { Alpha if Item } \\
\text { Deleted }\end{array}$ \\
\hline P1 & 28.18 & 7.865 & .322 & .200 & .720 \\
P2 & 28.22 & 6.910 & .476 & .410 & .689 \\
P3 & 27.78 & 7.930 & .301 & .180 & .723 \\
P4 & 28.06 & 7.323 & .505 & .395 & .685 \\
P5 & 28.02 & 6.714 & .494 & .349 & .685 \\
P6 & 27.74 & 7.707 & .354 & .207 & .714 \\
P7 & 27.60 & 7.918 & .308 & .304 & .722 \\
P8 & 28.26 & 6.972 & .619 & .491 & .663 \\
\hline
\end{tabular}

Sumber : Data primer yang diolah, 2017 
Tabel 4

Hasil Uji Validitas Variabel Motivasi

\begin{tabular}{|l|r|r|r|r|r|}
\hline & $\begin{array}{c}\text { Scale Mean if } \\
\text { Item Deleted }\end{array}$ & $\begin{array}{c}\text { Scale Variance if } \\
\text { Item Deleted }\end{array}$ & $\begin{array}{c}\text { Corrected Item- } \\
\text { Total Correlation }\end{array}$ & $\begin{array}{c}\text { Squared Multiple } \\
\text { Correlation }\end{array}$ & $\begin{array}{c}\text { Cronbach's } \\
\text { Alpha if Item } \\
\text { Deleted }\end{array}$ \\
\hline P1 & 27.56 & 16.619 & .510 & .372 & .817 \\
P2 & 27.52 & 15.234 & .596 & .552 & .804 \\
P3 & 27.30 & 16.378 & .499 & .308 & .817 \\
P4 & 27.40 & 15.429 & .563 & .380 & .808 \\
P5 & 27.44 & 15.925 & .451 & .433 & .823 \\
P6 & 27.84 & 15.076 & .660 & .624 & .797 \\
P7 & 27.44 & 14.619 & .655 & .457 & .796 \\
P8 & 27.86 & 12.939 & .596 & .445 & .813 \\
\hline
\end{tabular}

Sumber : Data primer yang diolah, 2017

Tabel 5

Hasil Uji Reliabilitas

\begin{tabular}{|c|l|l|l|}
\hline No & \multicolumn{1}{|c|}{ Variabel } & Cronbach's Alpha & \multicolumn{1}{|c|}{ Keterangan } \\
\hline 1 & Komitmen Organisasional & 0,780 & Reliabel \\
\hline 2 & Profesional & 0,792 & Reliabel \\
\hline 3 & Kepuasan kerja & 0,728 & Reliabel \\
\hline 4 & Motivasi & 0,829 & Reliabel \\
\hline
\end{tabular}

Sumber : Data primer yang diolah, 2017

Tabel 6

Hasil Regresi Linier Berganda

Coefficients $^{\mathrm{a}}$

\begin{tabular}{|c|c|c|c|c|c|c|}
\hline \multirow{2}{*}{\multicolumn{2}{|c|}{ Model }} & \multicolumn{2}{|c|}{ Unstandardized Coefficients } & $\begin{array}{c}\text { Standardized } \\
\text { Coefficients }\end{array}$ & \multirow[b]{2}{*}{$t$} & \multirow[b]{2}{*}{ Sig. } \\
\hline & & B & Std. Error & Beta & & \\
\hline \multirow[t]{4}{*}{1} & (Constant) & 7.433 & 2.474 & & 3.005 & .004 \\
\hline & K Organisasi & .219 & .150 & 230 & 1.462 & .151 \\
\hline & Profesi & .336 & 131 & 370 & 2.556 & 014 \\
\hline & Motivasi & .217 & .096 & .314 & 2.261 & .029 \\
\hline
\end{tabular}

a. Dependent Variable: Kep Kerja

Sumber: Data primer yang diolah, 2017

Tabel 7

Korelasi dan Determinasi Model Summary ${ }^{\text {b }}$

\begin{tabular}{|l|l|l|l|l|r|}
\hline Model & \multicolumn{1}{|c|}{$\mathrm{R}$} & \multicolumn{1}{c|}{ R Square } & Adjusted R Square & $\begin{array}{c}\text { Std. Error of the } \\
\text { Estimate }\end{array}$ & $\begin{array}{c}\text { Durbin- } \\
\text { Watson }\end{array}$ \\
\hline 1 & $.852^{\mathrm{a}}$ & .726 & .709 & 1.649 & 1.930 \\
\hline
\end{tabular}

a. Predictors: (Constant), Motivasi, Profesi, K Organisasi

b. Dependent Variable: Kep Kerja

Sumber: Data primer yang diolah, 2017 


\section{Tabel 8}

\section{Hasil Uji F (Simultan)}

ANOVA $^{\mathrm{D}}$

\begin{tabular}{|ll|r|r|r|c|c|}
\hline Model & & Sum of Squares & \multicolumn{1}{c|}{ df } & Mean Square & F & Sig. \\
\hline 1 & Regression & 331.944 & 3 & 110.648 & 40.707 & $.000^{2}$ \\
& Residual & 125.036 & 46 & 2.718 & & \\
& Total & 456.980 & 49 & & & \\
\hline
\end{tabular}

a. Predictors: (Constant), Motivasi, Profesi, K Organisasi

b. Dependent Variable: Kep Kerja

Sumber: Data primer yang diolah, 2017

\section{SIMPULAN}

Berdasarkan uraian dan hasil analisis pada bab - bab sebelumnya mengenai pengaruh komitmen organisasional dan profesional terhadap kepuasan kerja dengan motivasi sebagai variabel intervening pada pegawai UPT Dinas Kesehatan Puskesmas Air Bangis dapat diambil kesimpulan sebagai berikut:

1. Komitmen organisasional tidak berpengaruh terhadap kepuasan kerja pegawai UPT Dinas Kesehatan Puskesmas Air Bangis karena angka signifikansi sebesar 0,151 lebih besar dari level of signifikan 0,05 (Sig 0,151<0,05), maka dapat diambil kesimpulan bahwa komitmen organisasional secara parsial tidak berpengaruh terhadap kepuasan kerja pegawai UPT Dinas Kesehatan Puskesmas Air Bangis (Ho diterima dan Ha ditolak).

2. Profesional berpengaruh positif dan signifikan terhadap kepuasan kerja pegawai UPT Dinas Kesehatan Puskesmas Air Bangis karena angka signifikansi sebesar 0,014 lebih kecil dari level of signifikan 0,05 ( Sig 0,015 < $0,05)$, maka dapat diambil kesimpulan bahwa profesional berpengaruh positif dan signifikan secara parsial terhadap kepuasan kerja pegawai UPT Dinas Kesehatan Puskesmas Air Bangis (Ha diterima dan Ho ditolak).

3. Motivasi berpengaruh positif dan signifikan terhadap kepuasan kerja pegawai UPT Dinas Kesehatan Puskesmas Air Bangis karena angka signifikansi sebesar 0,029 lebih kecil dari level of signifikan 0,05 (Sig 0,015 < 0,05), maka dapat diambil kesimpulan bahwa motivasi berpengaruh positif dan signifikan secara parsial terhadap kepuasan kerja pegawai UPT Dinas Kesehatan Puskesmas Air Bangis (Ha diterima dan Ho ditolak).

\section{DAFTAR PUSTAKA}

Aziz, N. (2019). Pengaruh Lingkungan Kerja Terhadap Kinerja Yang Dimediasi Oleh Motivasi Kerja Karyawan Rocky Plaza Hotel Padang. https://doi.org/10.17605/OSF.IO/E4C59

Badjuri, Achmad, (2009), Pengaruh Perputaran Komitmen Organisasional, dan Profesional Terhadap Kepuasan Kerja Auditor dengan Motivasi Sebagai 
Variabel Intervening (Pada KAP di Jawa Tengah dan DIY), Skripsi, Jurusan Akuntansi, Universitas Stikubank Semarang.

Ciliana, (2008), Pengaruh Kepuasan Kerja, keterlibatan Kerja, Stres Kerja, dan Komitmen Organisasi Terhadap Kesiapan Individu Untuk Berubah, Skripsi, Universitas Indonesia.

Darmawan, Didit, (2013), Prinsip-prinsip Perilaku Organisasi, Pena Semestas, Surabaya.

Fendi, Z., \& Susanti, F. (2018). Pengaruh Kepuasan Kerja Terhadap Turnover Intention Dengan Komitmen Organisasi Sebagai Variabel Intervening Pada CV. Belibis Pariaman. https://doi.org/10.31227/osf.io/wumgx

Furqon, Muhamad, (2010), Pengaruh Komitmen Organisasional dan Profesional Terhadap Kepuasan Kerja Akuntan Publik dengan Sikap Perubahan Sebagai Variabel Intervening (Pada Kantor Akuntan Publik DKI Jakarta), Fakultas Ekonomi dan Bisnis, UIN Syarif Hidayatullah, Jakarta.

Ghozali, Imam, (2005), Aplikasi Analisis Multivariate Dengan Program SPSS, Edisi 3 , Semarang.

Handoko, T.H, (2001), Manajemen Personalia dan Sumber Daya Manusia, Edisi III, BPFE, Yogyakarta.

Hasibuan, Malayu S.P, (2003), Manajemen Sumber Daya Manusia, Bumi Aksara, Jakarta.

Irawati, Anik, Darmajaya, dan Supriadi, (2012), Pengaruh Orientasi Etika pada Komitmen Profesional, Komitmen Organisasional dan Sensitivitas Etika Pemeriksa dengan Gender sebagai Variabel Pemoderasi, Universitas Gadjah Mada, Yogyakarta.

Luthans, F, (2006), Organizational Behavior, (Mc. Hraw-Hill).

Muh, Taufik, Efendy, (2010), Pengaruh Kompensasi, Independensi, dan Motivasi Terhadap Kualitas Audit Aparat Inspektorat Dalam Pengawasan Keuangan Daerah (Studi Empiris Pada Pemerintah Kota Gorontalo), Universitas Diponegoro, Semarang.

Rachmawati, I.K, (2007), Manajemen Sumber Daya Manusia, CV.Andi Offset, Yogyakarta. 
Ridho, M., \& Susanti, F. (2019). Pengaruh Stres Kerja Dan Motivasi Kerja Terhadap Kepuasan Kerja Pada Karyawan Bank Mandiri Syariah Cabang Padang. https://doi.org/10.31227/osf.io/pa2cg

Robbins, S.P., and Judge, T.A, (2009), Perilaku Organisasi, Edisi Keempat, Salemba Empat, Jakarta.

Sugiyono, (2009), Metode Penelitian Pendidikan, Alfabeta, Jakarta.

Sutrisno, Edy, (2009), Manajemen Sumber Daya Manusia, Kencana, Jakarta.

Trianingsih, Sri, (2001), Pengaruh Komitmen Terhadap Kepuasaan Kerja Auditor : Motivasi Sebagai Variabel Intervening ( Studi Pada KAP Jawa Timur), Undip, Semarang.

Trianingsih, Sri, (2003), Pengaruh Komitmen Terhadap Kepuasan Kerja Auditor, Motivasi sebagai Variabel Intervening, Jurnal Riset Akuntasi Indonesia 6(2), pp: 199-216.

Wijayanti, Diah, (2008), Pengaruh Komitmen Terhadap Kepuasan Kerja Auditor Internal : Motivasi sebagai Variabel Moderating, SNA 11, Pontianak. 